\title{
Simulations of diamond heat spreader for the thermal management of GaN HEMT
}

\author{
Shirui $\mathrm{Pu}^{\mathrm{a}}$, Wenbo Luo ${ }^{\mathrm{b}}$, Yao Shuai ${ }^{\mathrm{c}}$, Chuangui $\mathrm{Wu}^{\mathrm{d}}$ and Wanli Zhang ${ }^{\mathrm{e}}$ \\ University of Electronic Science and Technology of China, State Key Laboratory of Electronic Thin \\ Films and Integrated Devices, 610054 chengdu, China \\ apsrupp@163.com, 'lwbstudyy@163.com, 'YaoShuaibest@163.com, 'wuchuanbe@163.com, \\ e873853197@qq.com
}

Keywords: diamond heat spreader, thermal management, GaN HEMT

Abstract. A diamond heat spreader has been combined with Si microchannel for the improvement of the hotspots cooling capability for GaN high power electronic devices. The effects of the diamond heat spreader and Si die have been simulated using steady model by finite element analysis. It was found that the diamond spreader can reduce the maximal temperature of $\mathrm{GaN}$ device. The effect of thickness of $\mathrm{Si}$ die on maximum gate temperature will be increases linearly with the increase of total power. These methodology shows promising way to cool AlGaN/GaN HEMTs on Si.

\section{Introduction}

In recent years, as modern electronic devices are becoming smaller and owning more functions, they are simultaneously facing significant increases in the integration, packaging density and heat fluxes. AlGaN/GaN high-electron mobility transistors (HEMTs) have been widely used for high power applications due to their wide bandgap and high breakdown field [1]. But, too high junction temperature caused by the self-heating effect will significantly reduce the drain current, transconductance, electron mobility and thermal conductivity of the transistor [2-5]. So, effective thermal management will be the key to ensuring perform well of devices [6].

A cooling solution of high thermal conductivity will be required to dissipate the concentrated high heat flux in the transistor [7]. CVD diamond have high thermal conductivity, which several times higher than $\mathrm{SiC}$ and $\mathrm{Si}$, can be utilized as the heat spreader for high heat flux microelectronic cooling [8-10]. In addition, the microchannel heat sink can dissipate high heat fluxes anticipated in high-power electronic devices [11]. So, combination of high thermal conductive materials and microchannels cooling can improve the thermal management effects.

\section{Layout and Simulation setup}

In this paper, schematic image of the cooling structure with diamond heat spreader and liquid-cooled Si microchannel heat sink is shown in Fig 1(a). The Si die, the diamond heat spreader and the Si microchannel heat sink are directly bonded together with Sn-based solders. A top view of the typical $\mathrm{AlGaN} / \mathrm{GaN}$ HEMT is shown schematically in Fig 1(b). The six heater of tiny area which evenly located on the center line is used to represent the gate finger heating area of the GaN HEMT, and each transistor is composed of 12 gate fingers of gate width $\mathrm{W}_{\mathrm{G}}$, gate length $\mathrm{L}_{\mathrm{G}}$, and gate-to-gate pitch $\mathrm{P}_{\mathrm{G}}$. In addition, each source and drain fingers are the same length $\mathrm{L}_{\mathrm{S} / \mathrm{D}}$, a $2 \mathrm{um} \mathrm{GaN}$ layer needs to be considered for GaN transistor [12]. Other geometrical parameters about cooling structure are list in Table 1. 
Table 1. Geometrical parameters of the cooling structure.

\begin{tabular}{|c|c|c|c|c|c|}
\hline Parameter & Definition & Value(um) & Parameter & Definition & Value(um) \\
\hline $\mathrm{L}_{\mathrm{Si} / \text { spreader/solder }}$ & $\begin{array}{c}\text { Length of } \\
\text { Si/spreader/solder }\end{array}$ & 6000 & $\mathrm{~L}_{\text {fin }}$ & Length of fin & 202.5 \\
\hline $\mathrm{W}_{\text {Si/spreader/solder }}$ & $\begin{array}{c}\text { Width of } \\
\text { Si/spreader/solder }\end{array}$ & 7200 & $\mathrm{~L}_{\text {heater }}$ & $\begin{array}{c}\text { Length of } \\
\text { HEMT }\end{array}$ & 505 \\
\hline $\mathrm{h}_{\mathrm{Si}}$ & Height of Si die & $50-400$ & $\mathrm{~W}_{\text {heater }}$ & $\begin{array}{c}\text { Width of } \\
\text { HEMT }\end{array}$ & 350 \\
\hline $\mathrm{h}$ & Height of spreader & $0-300$ & $\mathrm{P}_{\text {heater }}$ & $\begin{array}{c}\text { HEMT to } \\
\text { HEMT pitch }\end{array}$ & 700 \\
\hline $\mathrm{h}_{\text {solder }}$ & $\begin{array}{c}\text { Thickness of } \\
\text { Au/Sn solder }\end{array}$ & 3 & $\mathrm{~L}_{\mathrm{G}}$ & Gate length & 0.5 \\
\hline $\mathrm{L}_{\text {micro }}$ & $\begin{array}{c}\text { Length of } \\
\text { microchannel }\end{array}$ & 10000 & $\mathrm{~W}_{\mathrm{G}}$ & Gate width & 350 \\
\hline $\mathrm{W}_{\text {micro }}$ & $\begin{array}{c}\text { Width of } \\
\text { microchannel }\end{array}$ & 10000 & $\mathrm{~L}_{\mathrm{S} / \mathrm{D}}$ & $\begin{array}{c}\text { Source and } \\
\text { drain length }\end{array}$ & 25 \\
\hline $\mathrm{h}_{\text {micro }}$ & $\begin{array}{c}\text { Height of } \\
\text { microchannel }\end{array}$ & 1100 & $\mathrm{P}_{\mathrm{G}}$ & $\begin{array}{c}\text { Gate to gate } \\
\text { pitch }\end{array}$ & 40 \\
\hline $\mathrm{L}_{\text {channel }}$ & Length of channel & 400 & $\mathrm{~h}_{\mathrm{GaN}}$ & $\begin{array}{c}\text { Thickness of } \\
\text { GaN layer }\end{array}$ & 2 \\
\hline $\mathrm{W}_{\text {channel }}$ & $\begin{array}{c}\text { Width of channel } \\
\mathrm{h}_{\text {channel }}\end{array}$ & 10000 & $\mathrm{~h}_{\mathrm{AlGaN}}$ & $\begin{array}{c}\text { Thickness of } \\
\text { AlGaN layer }\end{array}$ & 0.03 \\
\hline Height of channel & 800 & $\mathrm{~h}_{\mathrm{Au}}$ & $\begin{array}{c}\text { Metallization } \\
\text { thickness }\end{array}$ & 1 \\
\hline
\end{tabular}

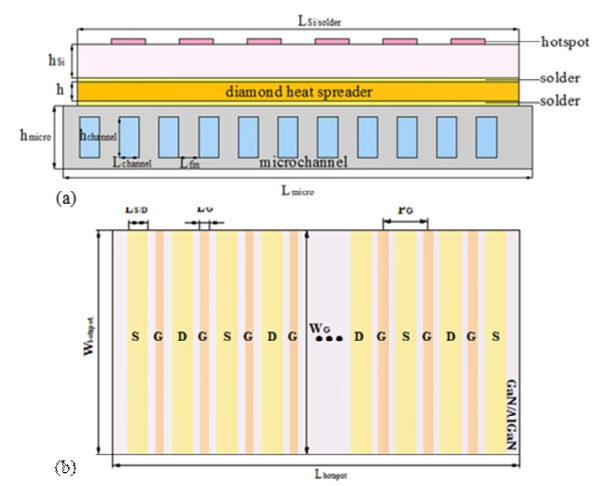

Fig. 1. Schematic drawing of the structures used in the numerical simulations.

(a) Schematic cross-sectional view of the simulation structure.

(b) Top view of the HEMT hotspot structure used in the simulation.

For the simulation model in this paper is constructed using ANSYS that runs the finite element analysis with adaptive meshing and error control. The convergence criterion of the Flow and Energy is $1 \mathrm{e}-3$ and 1e-7, respectively. Boundary conditions of the calculation region are set to adiabatic boundary condition and ignore radiation heat transfer. The temperature dependent thermal conductivities of materials are considered in the simulation, the values are list in Table 2 . The simulations are performed at the ambient temperature $20^{\circ} \mathrm{C}$ by putting six heaters simultaneously with $36 \mathrm{~W}$ total power. The liquid in the microchannel is $280 \mathrm{~K}$ water, velocity of flow in each channel is 0.2 $\mathrm{m} / \mathrm{s}$ and based on the estimated low Reynolds number in the heat sink with this flow velocity, the microchannel is considered to be operated in laminar regime. 
Table 2. Thermal conductivity for all materials.

\begin{tabular}{|c|c|}
\hline Material & $\begin{array}{c}\text { Thermal } \\
\text { conductivity }(\mathrm{W} / \mathrm{mK})\end{array}$ \\
\hline $\mathrm{GaN} / \mathrm{AlGaN}$ & $160 \times(300 / \mathrm{T})^{1.4}$ \\
\hline $\mathrm{Si}$ & $148 \times(300 / \mathrm{T})^{1.3}$ \\
\hline $\mathrm{Diamond}$ & $1832 \times(298 / \mathrm{T})^{1.305}$ \\
\hline $\mathrm{Au} / \mathrm{Sn}$ & 57 \\
\hline
\end{tabular}

\section{Results and discussion}

The steady state simulation is performed on the simulation model. The influence of the total power load in the hot spot on the maximum temperature as shown in Fig. 2. The temperature increases linearly with the increase of total power can be seen from the Fig. 2. Since many power devices have a high power, the device may work at high temperature, so the efficiency and stability of the device have greatly affected.
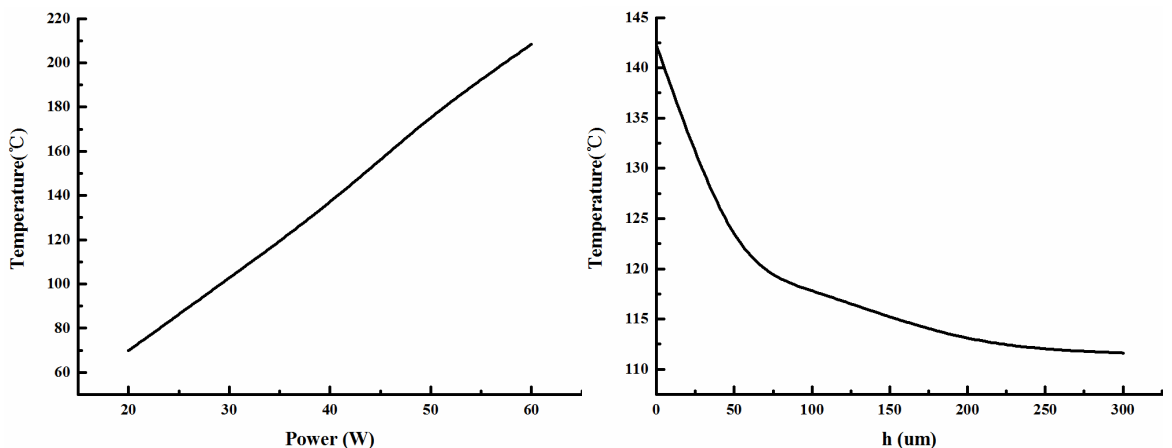

Fig. 2. Maximum temperature as a function of the total power for cooling structure with diamond heat spreader from simulation analysis.

Fig. 3. Maximum temperature as a function of the diamond heat spreader thickness $\mathrm{h}$ for a cooling structure.

The effect of diamond heat spreader thickness h on maximum heater temperature as shown in Fig 3. In this set of simulations, thickness of Si die hsi is $200 \mathrm{um}$. With the increase of diamond heat spreader thickness $\mathrm{h}$, the temperature gradually decreases and finally tends to be stable. A $50 \mathrm{um}, 100 \mathrm{um}, 200$ um and 300 um diamond heat spreader can reduce the temperature by $13 \%, 19.6 \%, 20.4 \%$ and $21.5 \%$, respectively. It is worth noting that heat dissipating capacity of diamond heat spreader tends to saturation when the $\mathrm{h}$ is above $250 \mathrm{um}$. We can see that the diamond heat spreader have heat dissipation performance for the high heat flux heater. Further investigations about heat dissipation performance of diamond heat spreader have been performed based on these simulation results, as shown in Fig 4.

Vertical temperature distributions were shown in Fig. 4. Lower temperature difference from the die top to the heat sink top has been achieved using the diamond heat spreader. Owing to the diamond heat spreader, the heat dissipating capability is highly enhanced, the temperature of each point in the vertical direction is lower than that of the without diamond heat spreader and the heat flux on the top surface of the Si microchannel heat sink is quite small and more uniform for the cooling structure. 

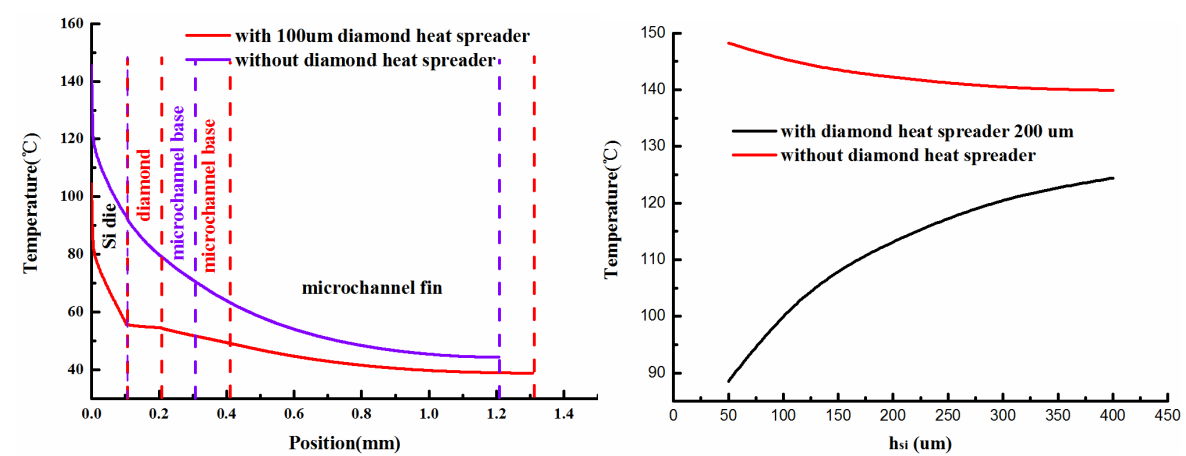

Fig. 4. Simulation of temperature distribution in the vertical direction with and without diamond heat spreader.

Fig. 5. Maximum temperature as a function of the $\mathrm{Si}$ die thickness $\mathrm{h}_{\mathrm{Si}}$ for a cooling structure.

Effect of thickness of Si die on maximum gate temperature as shown in Fig. 5. We can see that the maximum gate temperature rises with the increase of the Si die thickness at the 200 um diamond heat spreader. The thickness of $\mathrm{Si}$ die is reduced from $400 \mathrm{um}$ to $50 \mathrm{um}$, the maximum gate temperature is reduced from $124.4 \square$ to $88.6 \square$. We also can see that, maximum gate temperature reduced with the $\mathrm{Si}$ die thickness increase, but in the case of the same thickness of Si die, the structure of diamond heat spreader still has a lower maximum temperature. This is because the Si has a certain thermal conductivity, can play a weak role in dissipate heat, in the absence of material that has higher heat conductivity. Therefore, thinning of the Si die plays an important role in reducing junction temperature.

\section{Conclusion}

Higher power will result in higher operating temperatures, so a cooling structure combined diamond heat spreader with microchannel is proposed. Diamond has excellent thermal conductivity, the diamond as the heat spreader can significantly reduce the maximum temperature. Besides, lower temperature difference from the die top to the heat sink top has been achieved using the diamond heat spreader. So, diamond heat spreader have heat dissipation performance for the high heat flux hotspot. The thermal conductivity of $\mathrm{Si}$ is low, if the Si die is too thick, it will hinder the dissipate of heat. So, thinning of the Si die plays an important role in reducing junction temperature. Only use these two methods at the same time, can achieve a better cooling effect.

\section{References}

[1] M.S. Shur: GaN based transistors for high power applications, Solid State Electron, 42, 12 (1998) 2131-2138.

[2] J.W. Lee, K.J. Webb: A temperature-dependent nonlinear analytic model for AlGaN-GaN HEMTs on SiC, IEEE Transactions on Microwave Theory \& Techniques, 52, 1 (Jan 2004) 2-9.

[3] S.K. Islam, H.F. Huq: Improved temperature model of AlGaN/GaN HEMT and device characteristics at variant temperature, International Journal of Electronics, 94, 12 (Dec2007) 1099-1108.

[4] Y. Chang, Y. Zhang, Y. Zhang, KY. Tong: A thermal model for static current characteristics of AlGaNGaN high electron mobility transistors including self-heating effect, Journal of Applied Physics, 99, 4 (2006) 044501 - 044501-5.

[5] M.K. Chattopadhyay, S. Tokekar: Thermal model for dc characteristics of AlGaN/GaNHEMTs includingself-heating effect and non-linear polarization, Microelectronics Journal, 39 (2008) 1181-1188.

[6] R.H. Horng, J.S. Hong, Y.L. Tsai, et al. : Optimized thermal management from a chip to a heat sink for high-power GaN-based light-emitting diodes, Electron Devices IEEE Transactions on, 57, 9 (Sep 2010) 2203-2207.

[7] Z. Yan, G. Liu, J.M. Khan, A.A. Balandin: Graphene quilts for thermal managementof high-power GaN transistors, Nature Communications, 3, 3 (2012) 199-202. 
[8] K. Jagannadham: Multilayer diamond heat spreaders for electronic power devices, Solid State Electron, 42, 12 (1998) 2199-2208.

[9] A. Wang, M. J. Tadjer, F. Calle: Simulation of thermal management in AlGaN/GaN HEMTs with integrated diamond heat spreaders, Semiconductor Science \& Technology, 28 (2013) 869-881.

[10] K.S. Grishakov, V.F. Elesin, N.I. Kargin, et al. : Effect of a diamond heat spreader on the characteristics of gallium nitride-based transistors, Russian Microelectronics, 45, 1 (Jan2016) 41-53. [11] Y. Mizuno, I. Soga, S. Hirose, et al. : Si microchannel cooler integrated with high power amplifiers for base station of mobile communication systems, IEEE Electronic Components and Technology Conference. (Jun2011) 1541-1546.

[12] S.T. Sheppard, K. Doverspike, W.L. Pribble, et al. : High power microwave GaN/AlGaN HEMTs on semi-insulating silicon carbide substrates, IEEE Electron Device Letters, 20, 4 (1999) 161-163. 